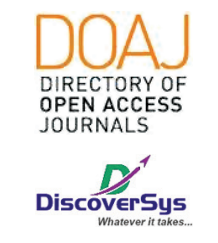

Published by DiscoverSys

\title{
Acute fatty liver of pregnancy: A case report
}

\author{
Putu Gede Agus Surya Mahardika, ${ }^{1 *}$ Aditya Prabawa,${ }^{2}$ Ketut Suardana ${ }^{3}$
}

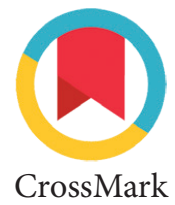

ABSTRACT

Introduction: Acute fatty liver of pregnancy (AFLP) is rare but potentially lethal complication. AFLP characterized by microvascular fatty infiltration of hepatocytes without any inflammation or necrosis. Case Presentation: A 37-year-old multigravida with 29 weeks period of gestation came with chief complains of acute jaundice, nausea, malaise and anorexia since 7 days ago. On examination, her eyes were icteric and her motor power was decreased on both extremities. Abdominal examination showed fetus in cephalic presentation with normal fetal heart rate. There was no opening and effacing of cervix. The ECG result showed prolonged QT interval. She had elevated liver enzyme, decreased renal function, electrolyte imbalance, hypoalbuminemia and hypercholesterolemia. Abdominal ultrasound was within normal limit. Patient was then assessed with differential diagnosed of AFLP, acute hepatitis and HELLP syndrome. She was treated conservatively with ferrous sulfate, high carbohydrate diet, KSR once daily, CDR once daily and Bisoprolol $1.25 \mathrm{mg}$ once daily. Three months later patient delivered a healthy baby boy via caesarian section due to premature rupture of membrane.

Conclusion: Since AFLP is a medical and obstetric emergency, early recognition and prompt treatment improves both maternal and fetal survival.

Keyword: acute fatty liver, pregnancy, LCHAD deficiency.

Cite This Article: Mahardika, P.G.A.S., Prabawa, A., Suardana, K. 2020. Acute fatty liver of pregnancy: A case report. Intisari Sains Medis 11(2): 835-838. D01: 10.15562/ism.v11i2.786

'Internship Doctor, Buleleng Regency Hospital, Bulleleng, Bali, Indonesia

${ }^{2} 0$ bstetrician and Gynecologist, Singaraja Army Hospital, Bali,

Indonesia

30bstetrician and Gynecologist, Buleleng General Hospital, Bali, Indonesia

${ }^{*}$ Correspondence to: Putu Gede Agus Surya Mahardika, Internship Doctor, Buleleng Regency Hospital, Buleleng, Bali, Indonesia suryamahardika092@gmail.com

Received: 2020-07-06 Accepted: 2020-07-29 Published: 2020-08-01

\section{INTRODUCTION}

Acute fatty liver of pregnancy (AFLP) is rare but potentially lethal complication which usually occur in third trimester or early postpartum period and may be part of a spectrum of preeclampsia related disorder. ${ }^{1}$ AFLP is characterized by microvascular fatty infiltration of hepatocytes without any inflammation or necrosis. The incidence rate of AFLP is approximately one in 10,000 to 15,000 pregnancies with mortality rate range from $7 \%$ to $58 \% .^{2}$ The mortality rate of AFLP is approximately $18 \%$ and deaths are usually secondary to sepsis, renal failure, circulatory collapse, pancreatitis or gastrointestinal bleeding. More than half (50-70\%) of AFLP is associated with pre-eclampsia with or without HELLP syndrome. Most of the affected women are also nulliparous and more common in twin pregnancies. ${ }^{3}$ AFLP may lead to hepatic failure and encephalopathy. The pathological features of AFLP are similar to those found in autosomal and inherited disorders of fatty acid oxidation. Hence, it was suggested that AFLP may result from defects in the $\beta$-oxidation of fatty acids. ${ }^{4}$ Clinical findings in AFLP may vary and overlap with HELLP syndrome thus making the diagnosis more challenging. In this case report, we would like to present a case of multigravida in her second trimester who developed AFLP.

\section{CASE PRESENTATION}

A 37-year-old multigravida with 29 weeks period of gestation was referred from a peripheral hospital to our primary hospital with chief complain of acute jaundice. Patient also complained about having nausea, malaise, anorexia and body weakness since 7 days ago. She could barely move her extremities since this morning. She also sometimes experienced abdominal pain but there was no vaginal spotting. There was no significant past history. She had a bad meal habit such as having big portion dinner with meat just an hour before sleep.

On examination, she was fully conscious with good orientation of place, time and person. She was well hydrated and afebrile. Her blood pressure was $100 / 60 \mathrm{mmHg}$ with pulse rate of 80 beats/minute. She had icteric sclera with no sign of anemia. Her respiratory rate was increased by 26 times/minute. Cardiovascular examination was normal. We found no edema and her extremities were warm. From neurological examination, we found her sensory ability was normal but her motor power was decreased which was five for both of her upper extremities and three for her lower extremities. Abdominal examination revealed relaxed uterus of 28 weeks period of gestation, with fetus in cephalic presentation and normal fetal heart rate. From vaginal examination, there was no opening and effacing of cervix. 
Her routine blood count examination was within normal limit with hemoglobin level of $12.1 \mathrm{~g} / \mathrm{dl}$, leucocyte count of $14,000 / \mathrm{mm}^{3}$ and platelet counts of $350,000 / \mathrm{mm}^{3}$. Her liver function test showed increased in SGOT/AST $213.5 \mathrm{U} / \mathrm{L}(10-34 \mathrm{U} / \mathrm{L})$ and SGPT/ALT 179.2 U/L (10-130 U/L). Kidney function tests revealed blood urea $13.9 \mathrm{~g} / \mathrm{dl}$, serum creatinine $1.37 \mathrm{mg} / \mathrm{dl}$. Her random blood sugar was $63 \mathrm{mg} / \mathrm{dl}$ and her albumin was low $(2.87 \mathrm{~g} / \mathrm{dL})$. Her electrolyte examination showed hyponatremia $132 \mathrm{mmol} / \mathrm{L}$ (135-145 mmol/L), hypokalemia $2.1 \mathrm{mmol} / \mathrm{L}(3.5-5.0 \mathrm{mmol} / \mathrm{L})$ and hypochloremia $87 \mathrm{mmol} / \mathrm{L}$ (96-106 mmol/L). She also had hypercholesterolemia with cholesterol level of $269 \mathrm{mg} / \mathrm{dL}$ $(<200 \mathrm{mg} / \mathrm{dL})$. Her TSHs level was normal which was $0.361 \mathrm{uIU} / \mathrm{mL}(0.350-4.040 \mathrm{uIU} / \mathrm{mL})$. Her viral hepatitis $\mathrm{C}$ markers (anti-HCV) was negative. Abdominal ultrasound was within normal limit.

The patient was then assessed with differential diagnosed of AFLP, acute hepatitis and HELLP syndrome. She had normal blood pressure throughout gestational and during hospital stay. The patient was then started on conservative management with ferrous sulfate and high carbohydrate diet. Patient were also referred to internist, neurologist and cardiologist. The internal department corrected

\begin{tabular}{|ll|}
\hline Variable & Finding \\
\hline Vomiting & Positive \\
\hline Abdominal pain & Positive \\
\hline Polydipsia/polyuria & Positive \\
\hline Encephalopathy & Positive \\
\hline Bilirubin & $>14 \mu \mathrm{mol} / \mathrm{L}$ \\
\hline Hypoglycaemia & $<4 \mathrm{mmol} / \mathrm{L}$ \\
\hline Uric acid & $>340 \mu \mathrm{mol} / \mathrm{L}$ \\
\hline Leucocytosis & $>11 \times 10^{6} / \mathrm{L}$ \\
\hline Liver ultrasonography & Ascites or bright \\
\hline AST and ALT & $>42 \mathrm{IU} / \mathrm{L}$ \\
\hline Ammonia & $>47 \mu \mathrm{mol} / \mathrm{L}$ \\
\hline Creatinine & $>150 \mu \mathrm{mol} / \mathrm{L}$ \\
\hline Coagulopathy & $>14 \mathrm{~s}$ \\
\hline PT & $>34 \mathrm{~s}$ \\
\hline APTT & Microvesicular steatosis \\
\hline Liver biopsy
\end{tabular}

Presence of $\geq 6$ of the Swansea criteria, in the absence of another explanation for liver dysfunction, confirmed the diagnosis of acute fatty liver of pregnancy (AFLP). ALT: alanine transaminase; APTT: activated partial thromboplastin time; AST: aspartate transaminase; PT: prothrombin time

Figure 1 Swansea criteria of AFLP ${ }^{14}$ her electrolyte imbalance with KSR once daily. The neurologist diagnosed her with periodic paraparesis caused by electrolyte imbalance and treat her with CDR once daily. The ECG result showed prolonged QT interval which was consistent with hypokalemia. Therefore, she was treated with Bisoprolol $1.25 \mathrm{mg}$ once daily. After one week of conservative treatment, patient was discharged and her laboratory examinations were within normal limit.

Approximately three months later, patient came back to the hospital with chief complain of watery discharge without any contraction since yesterday. On physical examination we found relaxed uterus of $38-39^{\text {th }}$ weeks period of gestation, with fetus in cephalic presentation and normal fetal heart rate. From vaginal examination, there was no opening and effacing of cervix. Litmus test was positive.

Routine blood count showed leukocytosis [leucocyte count was 13,7 (3,7-10,1)]. Other blood parameters where within normal limit. Liver function test, kidney function test, electrolyte level and hemostatic examination was also within normal limit. Patient only showed slight hypo albumin with albumin level of 3,20 (3,4-4,5 g/dL).

Patient was then diagnosed with G3P2A0 $38-39^{\text {th }}$ weeks of gestation and premature rupture of membrane. Patient was treated with analgesia and Cefuroxime $2 \times 750 \mathrm{mg}$. Patient then underwent cesarean section. Patient delivered a healthy baby boy with birth weight 3.200 gram and APGAR score of 7-8.

\section{DISCUSSION}

The incidence of AFLP is around 1 per 13.000 deliveries. AFLP has no distinctive epidemiologic features and may affect women of all ages and races. Mostly AFLP has the onset between $30^{\text {th }}$ and $38^{\text {th }}$ week of gestation. ${ }^{5}$ It is more frequent in primigravida than multigravida women. Several reports have also documented recurrence of AFLP in subsequent pregnancies. ${ }^{6}$

AFLP is an example of a primary mitochondrial hepatopathy. ${ }^{7}$ The exact pathogenesis of AFLP is still unknown. Most studies showed correlation between AFLP and mitochondrial dysfunction. Several reports have documented strong association between AFLP and deficiency of 3-hydroxyacyl-CoA-dehydrogenase (LCHAD) in the fetus, a disorder of mitochondrial fatty acid beta-oxidation. LCHAD acts as one of the mitochondrial trifunctional protein (MTP) which helps the oxidation process of fatty acids in the liver. ${ }^{4}$ These initial observations led to the hypothesis that 3-hydroxiy fatty acids accumulating in LCHAD deficient fetuses are toxic to the maternal liver. ${ }^{8}$ Recent studies now suggested that AFLP can occur 
without mutation of LCHAD. Interestingly, patients with AFLP generally recover from this condition after the delivery of the fetus which suggest a causative role of placenta. ${ }^{9}$ As we all know that placenta is essential for fetal development and it utilizes fatty acids as a metabolic fuel. Placental has identical genetic composition to that of the fetus, all of enzymes of mitochondrial fatty acid oxidation are expressed an active in human placenta. Therefore, defects in transport of fatty acids into the mitochondria or blocks at any steps of oxidation leads to accumulation of fatty acids and their metabolic products which could be toxic. ${ }^{10}$ Another study suggested the role of placental oxidative stress in the pathogenesis of AFLP. Compromised fatty acid metabolism in placental mitochondria of patients with AFLP would result in generation of oxidative stress in mitochondria. This compounds would then enter maternal circulation and result in hepatotoxicity. ${ }^{11}$

The clinical features of AFLP may vary and overlap with HELLP syndrome thus making the diagnosis of AFLP more challenging and complicated. It was reported that AFLP has a prodromal phase of 1-21 days before patients develop jaundice and hepatic failure if left untreated. ${ }^{12}$ The initial symptoms of AFLP can be misleading with non-specific symptoms like malaise, nausea, vomiting, flu-like illness, epigastric or abdominal pain, headache and pruritus. Hence, any pregnant women with nonspecific flu-like illness or vomiting in the second half of pregnancy should be carefully investigated for laboratory evidence of hepatic involvement. ${ }^{13}$ To help clinicians diagnose AFLP, Swansea criteria may come handy. The Swansea criteria includes vomiting, abdominal pain, polydipsia/polyuria, encephalopathy, elevated serum bilirubin level, elevated uric acid, hypoglycemia, leukocytosis, elevated transaminases, ascites or bright liver on USG, elevated ammonia, renal impairment, coagulopathy, and microvesicularsteatosis on liver biopsy in addition to metabolic acidosis and occasionally biochemical pancreatitis. Patients who develop at least six or more of this criteria are more likely to have AFLP. ${ }^{14}$

Patients with AFLP may have elevated serum aminotransferase, elevated white cell count and demonstrate thrombocytopenia and normoblasts in peripheral blood smear. ${ }^{15}$ It is recommended to check for patient's coagulation status such as PT, PTT and fibrinogen as disseminated intravascular coagulopathy (DIC) is relatively common. ${ }^{16}$ Blood urea nitrogen level, creatinine level, ammonia level and uric acid level may also increase. Patients may also experience hypoglycemia. Although the gold standard for definitive diagnosis of AFLP is through liver biopsy, it's not routinely done for obvious reason of urgent delivery and coagulopathy. Ultrasound, CT-scan and MRI have been considered as non-invasive tools for diagnosis of AFLP even though their value remain limited. ${ }^{17}$

Liver function test will slowly recover but may show and continue deteriorating for up to one week postpartum. Initially, liver enzymes, ammonia and coagulation studies will begin to normalize then renal function test will show some improvement as long as there is no permanent kidney damage. ${ }^{1}$ In the past, the neonatal mortality rate had been estimated to be as high as $85 \%$. However nowadays, with prompt recognition and treatment, the mortality rate has dramatically decreased to approximately $23 \% .{ }^{13}$ At the time of diagnosis, infants frequently experience severe liver failure, severe cardiomyopathy and hypoketotic hypoglycemic encephalopathy which may be difficult to reverse. ${ }^{18}$ Therefore, close fetal surveillance and neonatal care are essential.

The main differential diagnosis of AFLP are preeclampsia and HELLP syndrome. There are several ways to distinguished between those diagnoses. Transaminitis in AFLP is more profound than in pre-eclampsia and HELLP syndrome. The features of acute liver failure are more common in AFLP but rarely in HELLP. Hypoglycemia is distinctly uncommon in HELLP but it's often accompany AFLP. DIC also occurs in $70 \%$ of patients with AFLP and only $20-40 \%$ of patients with HELLP. ${ }^{18-20}$

Treatment of AFLP is largely supportive with or without corticosteroid and best carried out in critical care environment with multidisciplinary clinicians. Clinicians should pay careful attention to fluid balance, correcting clotting factors abnormalities and surveillance of hypoglycemia. Patients with encephalopathy should always be considered for intubation and mechanical ventilation. Careful selection on the optimal mode of delivery whether elective caesarean or vaginal birth depending on maternal coagulation and fetal status is recommended. ${ }^{3}$ Vaginal birth is probably the best approach if tolerated. However, caesarean birth is often performed because of rapidly deteriorating maternal-fetal status.

\section{CONCLUSION}

AFLP is a medical and obstetric emergency which require early diagnosis and prompt treatment to improve both maternal and fetal survival. Recent studies suggest fetal-maternal interaction as the pathogenesis of AFLP. Screening newborn babies in pregnancies complicated by AFLP for this fatty acid oxidation disorder can be lifesaving and may allow for genetic counseling in subsequent pregnancies. 


\section{CONFLICT OF INTEREST}

The author declares there is no conflict of interest regarding publication of current case report.

\section{ETHICAL CONSIDERATION}

Patient had received signed informed consent prior to any data collection.

\section{REFERENCES}

1. Hin Hin Ko EY. Acute fatty liver of pregnancy. Gastroenterology. 2006;20(1):25-30.

2. Knight M, Kurinczuk JJ, Spark P, Brocklehurst P. A prospective national study of acute fatty liver of pregnancy in the UK. 2008;951-6.

3. Rajasri AG, Srestha R, Mitchell J. Acute fatty liver of pregnancy (AFLP) - an overview. J Obstet Gynaecol (Lahore). 2007;27(April):237-40.

4. Ibdah JA. Acute fatty liver of pregnancy: An update on pathogenesis and clinical implications. World J Gastroenterol. 2006;12(46):7397-404

5. Knox T, Olans L. Liver Disease in Pregnancy. N Engl J Med. 2013;569-76.

6. Wilcken B, Leung K, Hammond J. Pregnancy and fetal longchain dehydrogenase deficiency. Lancet. 2010;(341):407-8.

7. Lee WS, Sokol RJ. Liver Disease in Mitochondrial Disorders. Semin Liver Dis. 2012;27(3):22-30.

8. Strauss AW, Bennett M, Rinaldo P, Sims HF, Brien LKO, Zhao Y, et al. Inherited Long-Chain 3-Hydroxyacyl-CoA Dehydrogenase Deficiency and a Fetal- Maternal Interaction Cause Maternal Liver Disease and Other Pregnancy Complications. Semin Perinatol. 2011;23(2):100-12.

9. Reyes H, Sandoval L, Wainstein A, Ribalta J, Donoso S, Smok G, et al. Acute Fatty Liver of Pregnancy: a Clinical Study of 12 Episodes in 11 Patients. BMJ Case Rep. 2010;35:101-6.

10. Ventura F, Ruiter J, Ijlst L. Inhibitory effect of 3-hydroxyacylCoAs and other long-chain fatty acid ] J-oxidation intermediates on mitochondrial oxidative phosphorylation. J Inherit Metab Dis. 2006;19:161-4.
11. Natarajan SK, Thangaraj KR, Eapen CE, Ramachandran A, Mukhopadhya A, Mathai M, et al. Liver Injury in Acute Fatty Liver of Pregnancy: Possible Link to Placental Mitochondrial Dysfuntion and Oxidative Stress. J Hepatol. 2010;51(1):191-200.

12. Castro MA, Fassett MJ, Reynolds TB, Shaw KJ, Goodwin TM. Reversible peripartum liver failure : A new perspective on the diagnosis, treatment, and cause of acute fatty liver of pregnancy, based on 28 consecutive cases. Am J Obstet Gynocology. 2010;389-95.

13. Fesenmeier MF, Coppage KH, Lambers DS, Barton JR, Sibai BM. Acute fatty liver of pregnancy in 3 tertiary care centers. Am J Obstet Gynocology. 2015;1416-9.

14. Laurie J, Morton A. Physiological changes of pregnancy and the Swansea criteria in diagnosing acute fatty liver of pregnancy. Obstet Med. 2018;2(1):22-6.

15. Burroughs A, Seong N, Dojcinov D, Scheuer P, Sherlock S. Idiopathic Acute Fatty Liver of Pregnancy in 12 Patients. Q J Med. 2016;51:481-97.

16. Holzbach R. Acute fatty liver of pregnancy with disseminated intravascular coagulation. Obstet Med. 2016;43(5): 740-5.

17. MA C, Colletti O, KJ S, SM S, TM G. Radiologic studies in acute fatty liver of pregnancy. A review of the literature and 19 new cases. J Reprod Med. 2015;41(11):839-43.

18. Vigil-de Gracia P. Acute fatty liver and HELLP syndrome : two distinct pregnancy disorders. Int J Gynaecol Obstet. 2011;73:215-20.

19. Moldenhauer JS, Brien JMO, Barton JR, Sibai B. Acute fatty liver of pregnancy associated with pancreatitis : A life-threatening complication. Am J Obstet Gynocology. 2010;190:502-5

20. Suzuki S, Watanabe S, Araki T. Acute fatty liver of pregnancy at 23 weeks of gestation. Br J Obstet Gynaecol. 2011; 108 (February): 223-4.

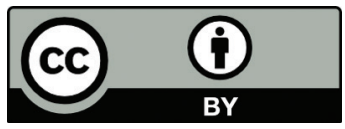

This work is licensed under a Creative Commons Attribution 